\title{
Review Article \\ Bulk Metallic Glasses and Their Composites: A Brief History of Diverging Fields
}

\author{
Douglas C. Hofmann \\ Jet Propulsion Laboratory, California Institute of Technology, MS 18-105, 4800 Oak Grove Drive, Pasadena, CA 91109, USA \\ Correspondence should be addressed to Douglas C. Hofmann; dch@jpl.nasa.gov
}

Received 12 November 2012; Accepted 13 December 2012

Academic Editor: Ram Gupta

Copyright (C) 2013 Douglas C. Hofmann. This is an open access article distributed under the Creative Commons Attribution License, which permits unrestricted use, distribution, and reproduction in any medium, provided the original work is properly cited.

Bulk metallic glasses (BMGs) and their derivative metal matrix composites (BMGMCs) are emerging high-performance engineering materials that are on the precipice of widespread commercialization. This review article discusses the origin of these materials and how their applications and research focus have divided into two distinct fields, one primarily focused on the plasticlike processability of BMGs and the other on the enhanced fracture mechanics of BMGMCs. Although the materials are of similar composition and origin, it is argued that their implementation will be widely varying due to their different processing requirements and intended uses. BMGs will likely find use as plastic-replacement components in cosmetic applications (e.g., watches, cell phones, biomedical implants) while BMGMCs will be used in structural applications (e.g., golf clubs, hardware for defense, energy absorbing structures).

Since 1960, with the first publication of a metallic glass system in $\mathrm{AuSi}$ [1], amorphous metals and their composites have produced widespread scientific and commercial interest [24]. Initially, the focus of research in this area was centered on rapidly quenched thin foils and ribbons of metallic glass and, in particular, the scientific curiosity of how deeply undercooled liquids could avoid nucleation and growth of crystals when cooled below their glass transition temperature $[5,6]$. Commercial applications soon followed with the identification of unique mechanical and magnetic properties obtained in thin layers of the materials. These included transformer coils produced by winding ribbons of $\mathrm{Ni}-, \mathrm{Co}^{-}$, and Fe-based metallic glasses and corrosion resistant spray coatings of glass-forming alloys on drilling pipes, for example [7]. Two decades of further research led to the development of multicomponent alloy compositions with deep eutectics, large atomic size mismatch between constituents and sluggish crystallization kinetics such that critical cooling rates to prevent crystallization could be reduced by orders of magnitude (from $10^{6}$ in quenched ribbons to $0.7 \mathrm{~K} / \mathrm{s}$ in $\mathrm{Pd}-\mathrm{Cu}-\mathrm{Ni}-\mathrm{P}$ ). These new alloys, identified as bulk metallic glasses (BMGs), exhibited robust glass-forming ability and could be fabricated at thicknesses greater than $1 \mathrm{~mm}$, thus creating a potential for structural hardware $[8,9]$. The development of BMGs in practical (low cost) alloy compositions, such as $\mathrm{Cu}-\mathrm{Zr}$ $\mathrm{Ni}-\mathrm{Al}$ and $\mathrm{Zr}-\mathrm{Ti}-\mathrm{Cu}-\mathrm{Ni}-\mathrm{Be}$, opened the door for widespread commercialization into applications such as cell phone cases and golf clubs. The surge in commercial interest, starting in the mid-1990s, identified a wide range of applications for BMGs but also identified a number of flaws in the material when used as structural hardware, particularly the low fracture toughness, low fatigue limit and complete lack of ductility $[10,11]$. Some research shifted towards toughening strategies for BMGs and in the early 2000s, progress was made by recognizing that the brittle failure of BMGs could be mitigated with the addition of crystalline phases into a BMG matrix [12]. This started a parallel field of research in BMG matrix composites (BMGMCs), with the aim of producing centimeter or greater thickness amorphous alloys for structural (load bearing) applications. Vigorous funding and increased world-wide research interest on BMGs and BMGMCs led to a resurgence in scientific progress on the materials by the end of the decade. Further understanding of the intricacies of processing amorphous metals has now brought us to the brink of global commercialization for these novel alloys and to a place where future activities in 
BMGs and their composites, while equally bright, diverge. BMGs are poised to make an impact in low-thickness, highprecision cosmetic applications usually reserved for polymers, while the high-strength, toughness, and hardness of BMGMCs are being investigated for high-performance loadbearing applications, such as spacecraft shielding and panels for military vehicles. Metallic glass coatings, in contrast, have already broken into the commercial marketplace with successful ventures achieved primarily in the oil and gas industry (see, e.g., websites for Armacor, Scoperta and the NanoSteel Company).

With access to infinite cooling rates, all metals and metal alloys can be undercooled into an amorphous state because crystal nucleation and growth are time dependent phenomena. Practically, the highest laboratory cooling rates that can be achieved to form a free-standing metal structure are obtained through splat or ribbon quenching, reaching initial cooling rates of $\sim 10^{7} \mathrm{~K} / \mathrm{s}$. Unfortunately, for all metallic elements (and most metal alloys), crystal nucleation and growth intervene on a shorter timescale than is achievable in the laboratory. The scientific breakthrough in this area was the identification of alloys with deep eutectics that could be undercooled to below their glass transition temperature at cooling rates of less than $10^{7} \mathrm{~K} / \mathrm{s}$ [5]. Successful fabrication of amorphous AuSi foils were obtained by splat quenching, a technique that involves levitating a metal droplet (0.25-1 g) using a conical induction coil, turning off the power to allow the droplet to fall through a laser beam, and splatting the droplet between two copper paddles to achieve amorphous foils $10-100 \mu \mathrm{m}$ in thickness, see Figure 1(a) [1]. Owing to the high laboratory cooling rates achieved through splatquenching, many alloy compositions were discovered that could be formed into thin foils, including alloys using lowcost elements such as Fe-Ni-B, Fe-Ni-P-B, and Ni-P [5]. The development of ribbon quenching techniques allowed these new alloys to be fabricated in hundreds-of-meters long strips, which are still commercialized today, see Figure 1(b). The ribbon quenching technique is a continuous casting process that involves spraying molten alloy onto a spinning copper wheel. The alloys cools from one side by the wheel and the other side is free-cooled, leading to similar cooling rates as the splat quenching technique $\left(\sim 10^{6} \mathrm{~K} / \mathrm{s}\right)$ but with the added improvement of continuous casting.

By the 1980s, some research focus in metallic glass research turned towards developing alloys that could be formed into bulk dimensions, typically greater than $1 \mathrm{~mm}$ in thickness or diameter $[5,6]$. Forming BMGs presented a major practical challenge because of the three orders of magnitude increase in the critical cooling rate needed to form bulk parts (e.g., $10^{7} \mathrm{~K} / \mathrm{s}$ in splat quenching to $10^{3} \mathrm{~K} / \mathrm{s}$ in copper mold casting). Early success in the fabrication of BMGs involved $\mathrm{Mg}$ or La-based alloys until practical $\mathrm{Zr}-\mathrm{Cu}-$ Al-Ni alloys were developed in 1990, followed by $\mathrm{Zr}-\mathrm{Ti}-\mathrm{Cu}-$ $\mathrm{Ni}$-Be alloys in 1993. In the new Zr-based BMGs, critical cooling rates could be as low as $1 \mathrm{~K} / \mathrm{s}$ to vitrify the alloys, which opened the door for die-casting-type processes for fabrication of net-shaped hardware. Alloy rods of up to $85 \mathrm{~mm}$ diameter have been demonstrated in the best glass-forming system yet known, Pd-Cu-Ni-P, which exhibits the lowest known critical cooling rate $(0.067 \mathrm{~K} / \mathrm{s})$ [5-7]. In the last three decades, dozens of alloys systems have been discovered that can be formed into BMGs, including ferromagnetic alloy systems (Fe-, Ni-, and Co-based), precious metals systems (Au-, Ag-, Pd-, Pt-based), and practical systems (Ti-, Cu-, and Zr-based). Commercial applications for BMGs, starting in the late 1990s by Liquidmetal Technologies, in California, and several Japanese ventures, demonstrated the promise of the new materials [6, 7]. Applications ranging from golf clubs, springs, optical devices, cell phone cases, biomedical implants, sporting equipment, and so forth were quickly developed through a variety of die-casting methods. The unique chemistry of BMGs made them ideal materials for applications typically held by polymers. BMGs exhibit low melting temperatures (which means that simple $\mathrm{Cu}$ or steel molds can be used repeatedly with little wear), low viscosities in the melt (which allows for easy mold filling and complex net-shaped parts), low critical cooling rates (which means parts up to several centimeters thick can be made amorphous), and excellent mechanical properties when cooled into the amorphous state (high strength, hardness and surface finish). Figure 2 shows several BMG parts sitting on a $\sim 1 \mathrm{~m}^{2}$ plate of die-cast Vitreloy 1 (parts fabricated by Liquidmetal Technologies and Howmet). The parts shown include a golf club driver, an iron, a USB hard drive case, a camera body, an optical device, eight ingots of feedstock, and a $12 \mathrm{~mm}$ diameter rod, all from the alloy Vitreloy 1 (trade name LM1). Figure 3 shows die-cast BMG components used to fabricate a watch.

Despite the initial promise of replacing plastics, as was the early objective, the widespread commercialization of BMGs did not happen because of several unforeseen drawbacks. It is now known that the mechanical properties of BMGs (particularly fracture toughness and fatigue limit) are highly dependent on material quality, oxygen content and the presence of unwanted phases or partial crystallization [10, 11]. This presents a major challenge to commercial manufacturing because lower quality material is typically used to make products cost-competitive. Moreover, large-scale diecasting generally involves melting crucibles and low-vacuum systems, which add contaminants and oxygen to BMGs. High volume parts made from BMGs can become brittle if low-quality material is used and unwanted phases can tarnish the cosmetic finish usually desired from consumer hardware. Despite these shortcomings, BMGs (of any quality or composition) are inherently brittle, which limits any application where a part may be subjected to unconfined (tensile) loads. Owing to a lack of microstructure to stop crack formation, no monolithic metallic glass exhibits significant ductility in tension, despite some alloys that have large fracture toughness. Currently, there are now well-established correlations between thickness, fracture toughness, plastic zone size and bending ductility, which demonstrates that in plates or rods greater than $\sim 3 \mathrm{~mm}$ in thickness, BMGs fail in a brittle manner [13-16]. Although these problems have been addressed recently by creating ultratough BMGs and designing applications for BMGs to be under $3 \mathrm{~mm}$, the solution in the early 2000s was to develop BMG composites, 


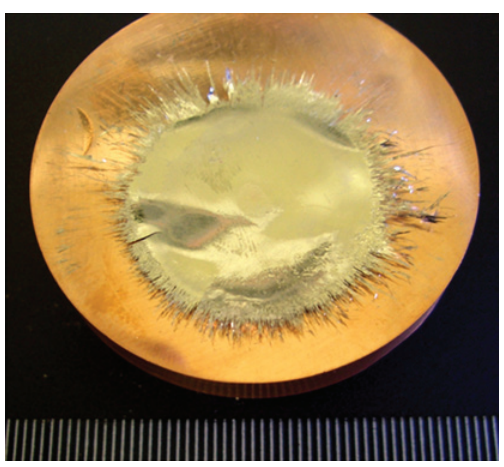

(a)

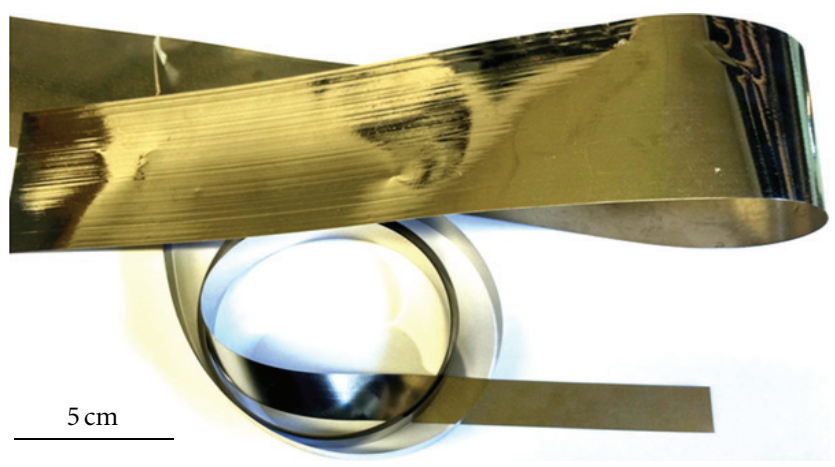

(b)

Figure 1: (a) A splat quenched foil of the Fe-based metallic glass. (b) Commercially available ribbons of the metallic glass Metglas 2826 in different thicknesses and widths. Samples courtesy of Allied Metglas.

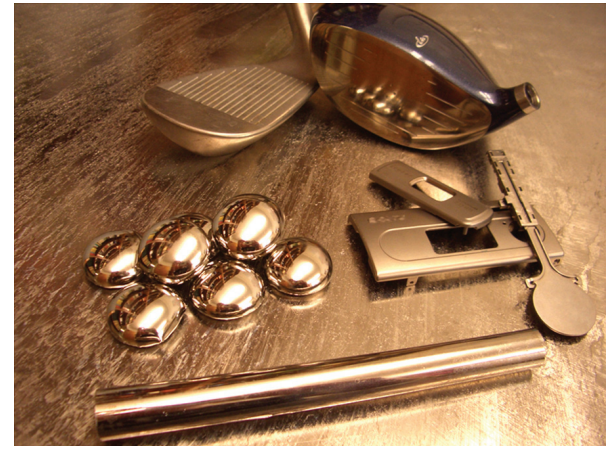

FIGURE 2: Examples of bulk metallic glass hardware, including golf clubs, electronic casings, optical hardware, ingots, $12 \mathrm{~mm}$ diameter rod, and large plate (under the samples). Hardware courtesy of Liquidmetal Technologies.

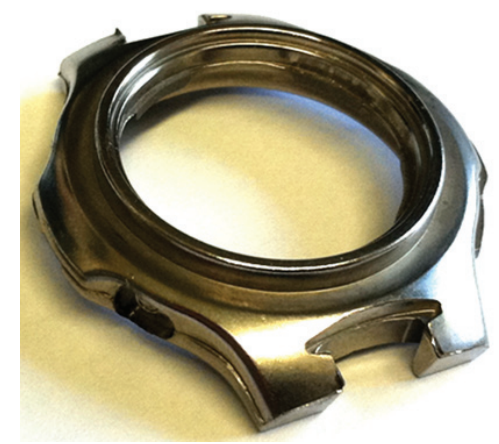

FIGURE 3: A net-shaped cast of a watch case directly out of the mold with no finishing or polishing. Hardware courtesy of Liquidmetal Technologies.

where additional phases could be selectively added to BMGs to arrest crack propagation.

The ideas of a partially crystalline metallic glass or a combination of metallic glass with some inclusion have been around nearly as long as metallic glasses. Early annealing experiments to study the glassy structure resulted in partial crystallization while other composites were stumbled upon through alloy development. In the late 1990s, attempts were made at developing "ex situ" composites, where BMGs were infiltrated over wires or powders of various crystalline materials to create two-phase mixtures $[17,18]$. Compression tests from two ex situ BMG composites reinforced with different volume fractions of soft $\mathrm{Zr}-\mathrm{Nb}$ particles is shown in Figure 4(a). Despite shear band formation and plasticity in bending, Figure 4(b), tensile ductility is absent. The addition of wires and particles was intended to improve the plastic strain associated with failure in the BMG but also to increase the density for possible kinetic energy penetrator (KEP) applications, when $\mathrm{W}$ or Ta wires were used. These ex situ BMG composites showed some improvement in compressive plasticity over monolithic BMGs, but ductility in tension was still absent unless the wires spanned the length of the rod, creating an iso-strain loading configuration and a "rule-of-mixtures" ductility. The major breakthrough in the formation of BMG composites was the development of "in situ" matrix composites (BMGMCs), where a secondphase dendritic structure could grown in equilibrium with a glass forming alloy [12]. This was accomplished by utilizing chemical decomposition in $\mathrm{Zr}$-Ti-Cu-Ni-Be, recognizing that $\mathrm{Cu}, \mathrm{Ni}$, and $\mathrm{Be}$ have little or no solubility in the body centered cubic (bcc) phase of Zr-Ti. By increasing the concentration of $\mathrm{Zr}$ and $\mathrm{Ti}$, while reducing $\mathrm{Cu}, \mathrm{Ni}$, and $\mathrm{Be}$, a thermodynamic equilibrium is created between bcc dendrites and a eutectic liquid. When quenched, the eutectic vitrifies as a glass matrix with the dendrites evenly spaced within. The first toughened in situ BMGMCs were developed by Hays and Kim at Caltech in 1999 (later published in 2000), by recognizing that the dendritic phase could be softened relative to the BMG matrix by adding a beta stabilizer, $\mathrm{Nb}$. The six component BMGMC $\mathrm{Zr}_{56.2} \mathrm{Ti}_{13.8} \mathrm{Nb}_{5} \mathrm{Cu}_{6.9} \mathrm{Ni}_{5.6} \mathrm{Be}_{12.5}$ (60\% BMG, 40\% bcc) was the first alloy of metallic glass to exhibit both the high tensile strength of BMGs, but also significant necking in tension ( 3\%) [19]. This discovery started the parallel field of BMG composites, for those researchers interested in improving the mechanical properties of amorphous metals for structural applications. 


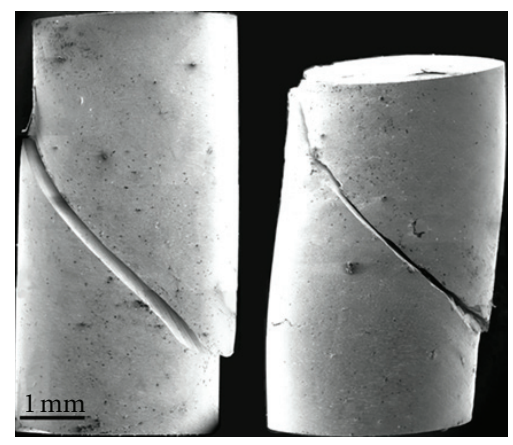

(a)

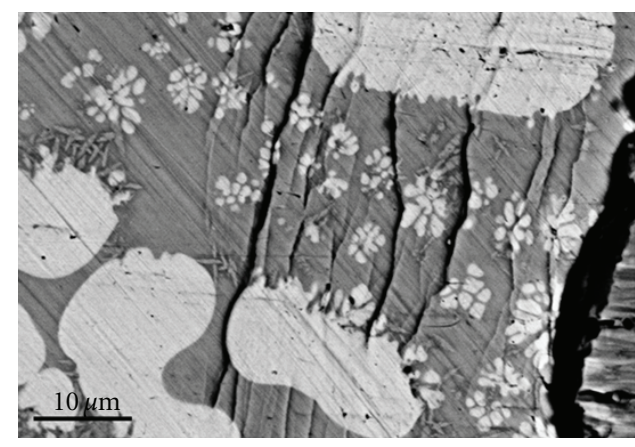

(b)

Figure 4: (a) Ex situ metallic glass matrix composites exhibiting different volume fractions of soft particles and therefore, different levels of compressive plasticity. (b) SEM micrograph of a particle-reinforced ex situ metallic glass matrix composite exhibiting shear band arresting. Smaller dendrites and needle crystal phase are also present.

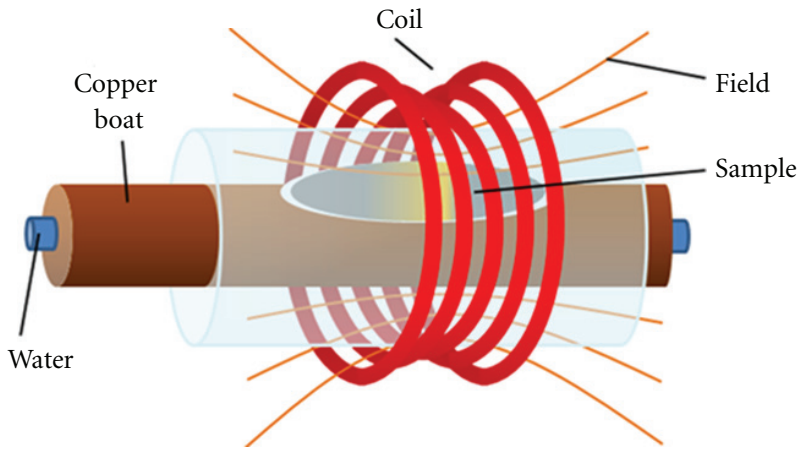

(a)

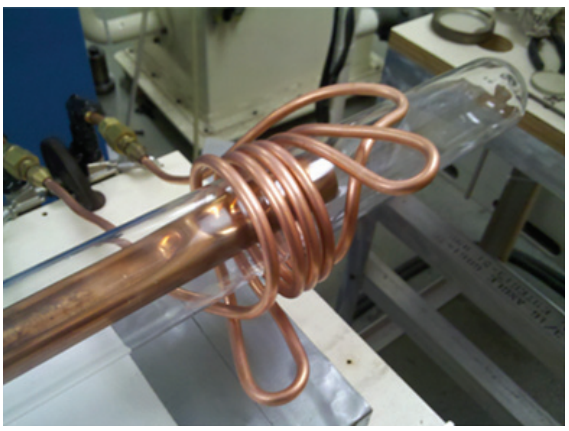

(b)

Figure 5: (a) Diagram of a water-cooled copper boat used for semisolid processing of in situ metallic glass matrix composites. (b) Example of a custom coil on a water-cooled copper boat.

During the early 2000s, research in amorphous metals increased dramatically, with numerous countries supporting large research efforts and university professors (USA, UK, Germany, China, Korea, etc.). However, despite early promise, commercial applications for BMGs did not become widespread due to problems with material cost, quality, production volume, and toughness, among others. Progress in BMGMCs was also hampered by a number of scientific issues which prevented significant improvements over the $\mathrm{Zr}_{56.2} \mathrm{Ti}_{13.8} \mathrm{Nb}_{5} \mathrm{Cu}_{6.9} \mathrm{Ni}_{5.6} \mathrm{Be}_{12.5}$ composite published in 2001 . Although many BMGMCs were discovered in a variety of systems, these alloys did not outperform the original alloy in terms of mechanical properties such as strength and ductility [20-25]. The primary reasons for this included the unique chemistry of Be-bearing composites, the composition of the dendrites, the length scale of the dendrites, and the toughness of the glass matrix. By 2007, progress was made in the emerging parallel field of BMGMCs by developing a series of guidelines for creating toughened composites [26]. (1) The composite system needs a highly processable monolithic metallic glass with sluggish crystallization. Zr-Bebased composites are optimal for BMGMC formation due to the lack of stable compounds between the constituents and $\mathrm{Be}$, which prevents heterogeneous nucleation triggered by the dendrites during quenching. (2) The composite system needs a stable crystal that does not cause heterogeneous nucleation of the matrix. These dendrites can be formed in equilibrium two-phase systems, or by partially crystallizing the BMG during cooling. (3) The shear modulus $(G)$ of the dendrite needs to be lower than the matrix. The inclusion needs to be soft relative to the matrix such that cracks are "attracted" to them, rather than propagating through the matrix alone. (4) The microstructure should be coarsened to match the inclusion size and spacing with the plastic zone size (critical shear band length) of the BMG matrix. This rule was developed by observing a cooling rate dependence on the scale of the dendrites in a BMGMC. When cooled from the liquidus, time for nucleation and growth is limited, creating a microstructure that varies throughout the quenched sample depending on the local cooling rate. The major breakthrough was the understanding that toughness was related to the size of these dendrites, and that regions where they were coarser produced higher toughness. This led to the development of semisolid processing, an intermediate quenching step where the BMGMC is held just above the solidus temperature in the two-phase region and the dendrites are allowed to thermodynamically coarsen prior to final quenching, see Figure 5. This procedure proved extremely successful at creating large 


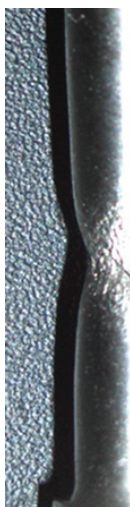

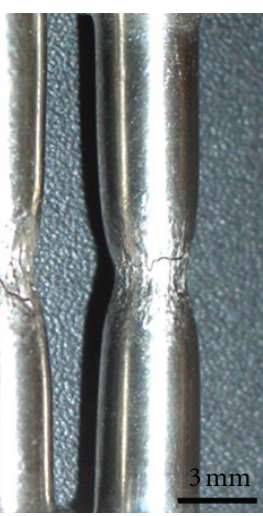

(a)

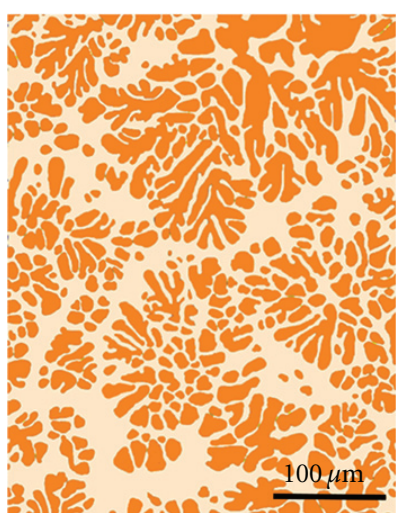

(b)

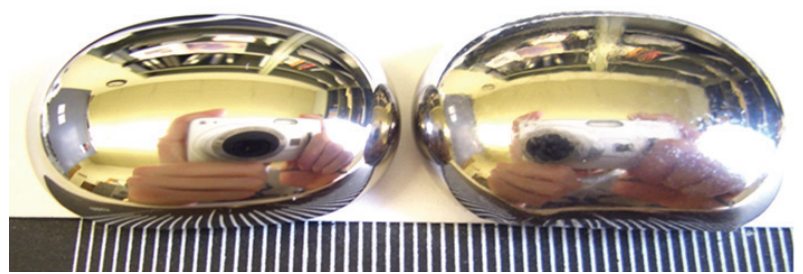

(c)

FIGURE 6: (a) Necking in tension from two different $\mathrm{Zr}$-Ti-Nb-Cu-Be bulk metallic glass matrix composites. (b) Contrast adjusted SEM micrograph of the dendrite structure in a bulk metallic glass matrix composite. (c) Comparison in surface appearance between a monolithic metallic glass (left) and an in situ composite. Both alloys were cooled from the liquidus state using an arc melter.

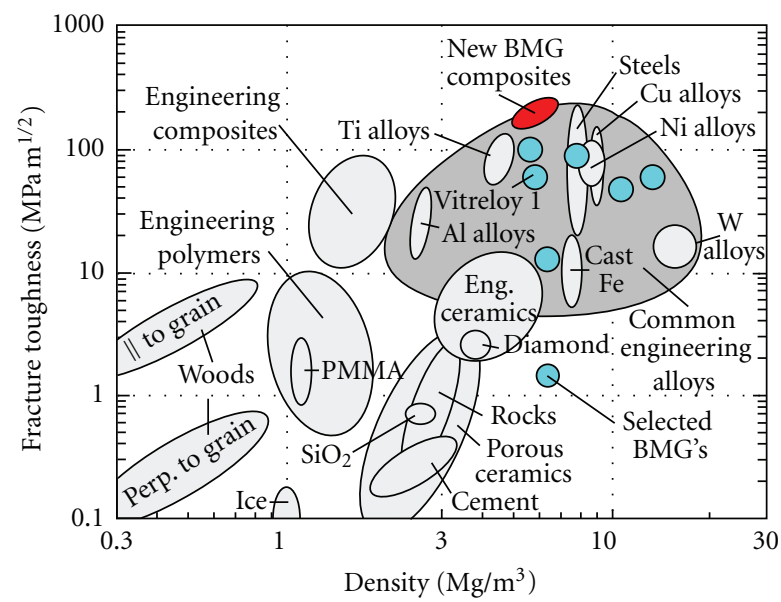

(a)

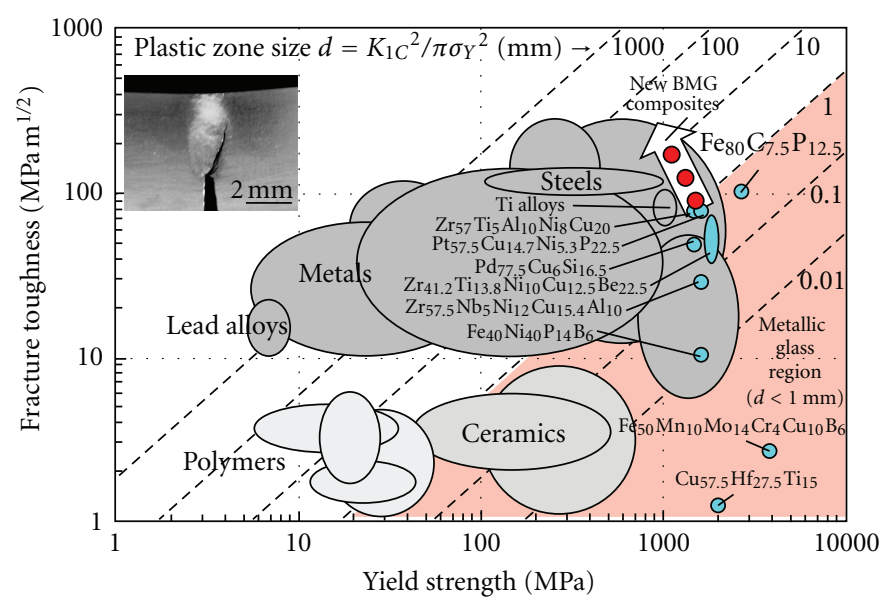

(b)

Figure 7: (a) Ashby map of fracture toughness versus density showing the location of select bulk metallic glasses and $\mathrm{Zr}$-Ti-Nb-Cu-Be bulk metallic glass matrix composites. The composite alloys have among the highest fracture toughness for their density. (b) Ashby map of fracture toughness versus yield strength showing select metallic glasses and composites. Contour lines indicate plastic zone size and the shaded region signifies the $d<1 \mathrm{~mm}$ region that typically confines monolithic metallic glasses. The plastic zone size of the toughened composites is shown in the inset.

coarsened microstructures and ductility in BMGMCs was increased to $>10 \%$ while fracture toughness increased to $>160 \mathrm{MPa} \mathrm{m}^{1 / 2}$ [27]. (5) There also must be a suitably high fracture toughness interface between the inclusion and the BMG matrix such that crack growth does not proceed along the boundary of the inclusions. This rule was developed to explain the lack of ductility observed in powder-reinforced ex situ BMGMCs, even those where the size and composition of the dendrite matches the in situ composite. Oxide layers or porosity at the interface between the inclusions and the matrix generally leads to cracks propagating along the boundaries. Figure 6 shows images from a BMGMC, termed $\mathrm{DH} 1\left(\mathrm{Zr}_{36.6} \mathrm{Ti}_{31.4} \mathrm{Nb}_{7} \mathrm{Cu}_{5.9} \mathrm{Be}_{19.1}\right)$ with significant necking in tension (Figure 6(a)) due to the distribution of soft dendrites, shown in Figure 6(b) using a color adjusted scanning electron microscope image. BMGMCs, which generally contain at least $40 \%$ crystal phase, exhibit a rough surface when cooled in an ingot form, compared with a monolithic BMG which exhibits a perfect mirror finish, see Figure 6(c).

Recent progress in both monolithic BMGs and BMGMCs, particularly in the area of processing, would seem to indicate a bright future for these materials. The field of BMGs is poised to have widespread applications in the areas of consumer electronics, jewelry, fuel cells, coatings, and nano/microtechnology due to a much greater understanding of both the material properties and their processing potential. New toughened BMGMCs are now being investigated for high-performance structural applications in the areas of defense, aerospace, aeronautics, automotive, and sporting equipment. These include energy 

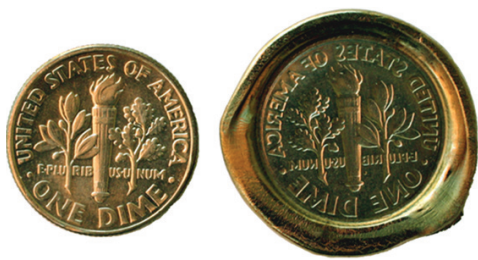

(a)

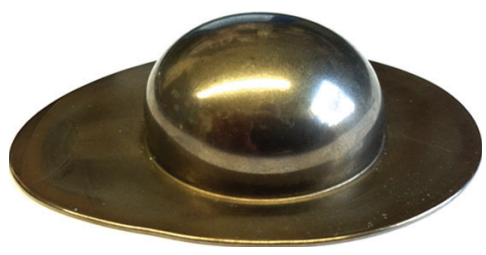

(b)

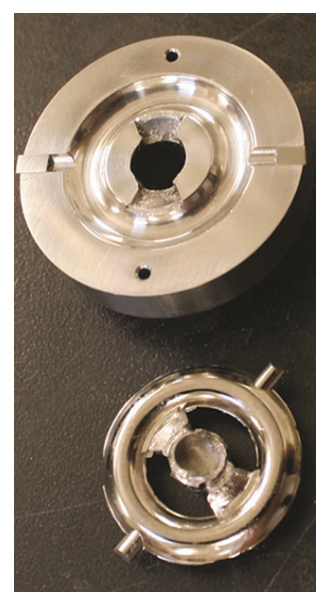

(c)

Figure 8: (a) Thermoplastic processing in a Zr-Ti-Cu-Be bulk metallic glass. (b) Blow molding demonstrated in a Zr-Ti-Cu-Be bulk metallic glass. (c) Capacitive discharge forming of a metallic glass showing the part and the mold in which it was cast in 40 milliseconds. These are all demonstrations of thermoplastic processing. Images from G. Duan and M.D. Demetriou.

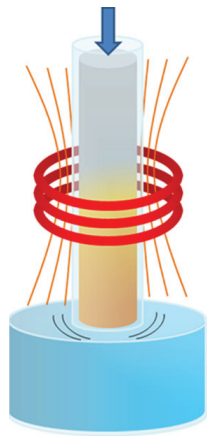

(a)

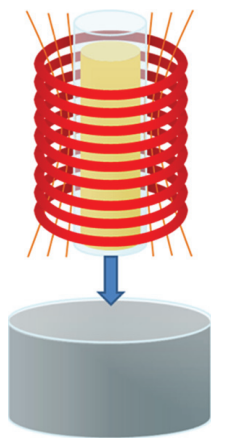

(b)

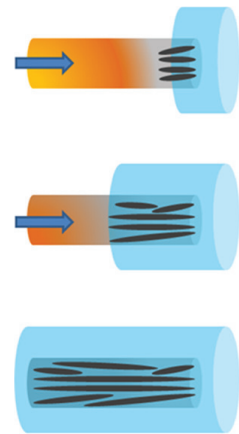

(c)

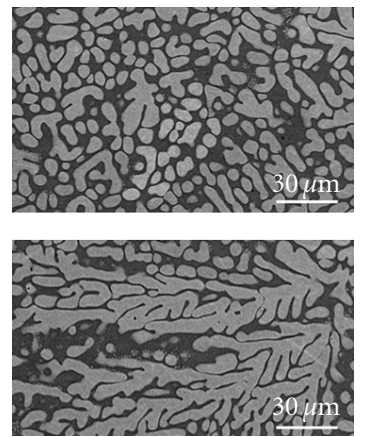

(d)

FIgURE 9: (a-b) Schematics of directional solidification of bulk metallic glass composites into water and a liquid metal bath. (c) Schematic of dendrite growth under directional solidification. (d) SEM micrographs from a bulk metallic glass matrix composite with no texture (top) and directional texture (bottom).

absorbing cellular structures, spacecraft debris shielding, golf clubs, car door panels, gears, armor, and penetrators. Ashby maps for fracture toughness versus density and fracture toughness versus yield strength are shown in Figures 7 (a) and 7(b). Several BMGs are shown along with the new BMGMCs based in $\mathrm{Zr}$-Ti-Cu-Nb-Be (termed DH1-3) [27]. These maps demonstrate how amorphous alloys and composites compare with all other known engineering materials in terms of toughness, density, and strength. In the case of the toughened BMG composites, the maps show that their properties lie at the boundaries with all available materials, including plastic zone size, $d$, which has limited BMG use in thicknesses greater than $1 \mathrm{~mm}$.

The processing possibilities of monolithic BMGs have been the focus of considerable research effort in recent years. New capabilities for casting samples from the molten state, including tilt casting [28], squeeze casting, injection casting, and so forth, have resulted in high-quality, tough parts with excellent cosmetic finishes. These have included cell phone cases, hollow tubes, sensors, and plates [6]. Enormous progress has also been made in the area of thermoplastic processing, which involves heating a BMG to the supercooled liquid region between the glass transition and the crystallization temperatures and forming it like a plastic, see Figure 8(a) [29-41]. Thermoplastic forming has been used in a variety of novel ways recently, including blow molding, shown in Figure 8(b) [30]. This technique has been used to make BMG bottles, holograms, spheres, and hollow watch cases [35, 39, 41]. Recently, rapid discharge forming (RDF) was demonstrated as a new technique to heat and thermoplastically process a BMG in milliseconds, which takes advantage of the near constant resistivity as function of temperature in metallic glasses to create uniform volumetric heating, Figure 8(c) [29]. Thermoplastic forming has also been used recently to develop micro and nano applications for metallic glasses [39]. Since BMGs are liquids when formed, there is no limit to the scale of features that can be fabricated. Successful demonstrations have included nanowires, microgears, MEMS devices, ultrasmooth surfaces, and large area fuel cells [29-41]. A large number of worldwide commercial and government ventures 
to create hardware from BMGs demonstrates the continued interest in turning amorphous metals into everyday objects.

New processing techniques and alloy compositions have also driven progress in BMGMCs. A recent breakthrough was obtained by creating a composite with a ductile shape memory alloy phase in $\mathrm{Cu}-\mathrm{Zr}-\mathrm{Al}-\mathrm{Co}[42,43]$. This alloy, along with another demonstration in Ti-Zr-Ni-Ta-Be, illustrate that transformation induced plasticity (TRIP) is also possible in BMGMCs. Numerous research studies have been undertaken to understand semisolid processing strategies in BMGMCs [44-49]. These have included directional solidification, Bridgman solidification, semisolid forging, squeeze casting, and electrostatic levitation, among others, see Figure 9 [44-49]. Continued government funding in the USA, from agencies such as NASA, the Office of Naval Research, and the Office of Air Force Scientific Research, demonstrates the promise for BMGMCs while widespread commercial interest may soon transform these materials into everyday hardware.

\section{Acknowledgments}

This work was supported by the Jet Propulsion Laboratory, California Institute of Technology, NASA's Exploration Systems Mission Directorate, under Contract no. NNH10ZTT001N and by the Air Force Office of Scientific Research under Grant no. RF01152700/PO60020925.

\section{References}

[1] W. Klement, R. H. Willens, and P. Duwez, "Non-crystalline structure in solidified Gold-Silicon alloys," Nature, vol. 187, no. 4740, pp. 869-870, 1960.

[2] M. Telford, “The case for bulk metallic glass," Materials Today, vol. 7, no. 3, pp. 36-43, 2004

[3] Y. H. Liu, G. Wang, R. J. Wang, D. Q. Zhao, M. X. Pan, and W. H. Wang, "Super plastic bulk metallic glasses at room temperature," Science, vol. 315, no. 5817, pp. 1385-1388, 2007.

[4] H. Guo, P. F. Yan, Y. B. Wang et al., "Tensile ductility and necking of metallic glass," Nature Materials, vol. 6, no. 10, pp. 735-739, 2007.

[5] A. Inoue, "Stabilization of metallic supercooled liquid and bulk amorphous alloys," Acta Materialia, vol. 48, no. 1, pp. 279-306, 2000.

[6] A. Inoue and A. Takeuchi, "Recent development and application products of bulk glassy alloys," Acta Materialia, vol. 59, no. 6, pp. 2243-2267, 2011.

[7] N. Nishiyama, K. Amiya, and A. Inoue, "Novel applications of bulk metallic glass for industrial products," Journal of NonCrystalline Solids, vol. 353, no. 32-40, pp. 3615-3621, 2007.

[8] A. Peker and W. L. Johnson, "A highly processable metallic glass: $\mathrm{Zr}_{41.2} \mathrm{Ti}_{13.8} \mathrm{Cu}_{12.5} \mathrm{Ni}_{10.0} \mathrm{Be}_{22.5}$, Applied Physics Letters, vol. 63, no. 17, pp. 2342-2344, 1993.

[9] H. B. Lou, X. D. Wang, F. Xu et al., "73 mm-diameter bulk metallic glass rod by copper mould casting," Applied Physics Letters, vol. 99, Article ID 051910, 2011.

[10] C. A. Schuh, T. C. Hufnagel, and U. Ramamurty, "Mechanical behavior of amorphous alloys," Acta Materialia, vol. 55, no. 12, pp. 4067-4109, 2007.
[11] P. Lowhaphandu and J. J. Lewandowski, "Fracture toughness and notched toughness of bulk amorphous alloy: $\mathrm{Zr}-\mathrm{Ti}-\mathrm{Ni}$-CuBe," Scripta Materialia, vol. 38, no. 12, pp. 1811-1817, 1998.

[12] C. C. Hays, C. P. Kim, and W. L. Johnson, "Microstructure controlled shear band pattern formation and enhanced plasticity of bulk metallic glasses containing in situ formed ductile phase dendrite dispersions," Physical Review Letters, vol. 84, no. 13, article no. 2901, 2000.

[13] M. D. Demetriou, G. Kaltenboeck, J. Y. Suh et al., "Glassy steel optimized for glass-forming ability and toughness," Applied Physics Letters, vol. 95, no. 4, Article ID 041907, 2009.

[14] R. D. Conner, Y. Li, W. D. Nix, and W. L. Johnson, "Shear band spacing under bending of Zr-based metallic glass plates," Acta Materialia, vol. 52, no. 8, pp. 2429-2434, 2004.

[15] R. D. Conner, W. L. Johnson, N. E. Paton, and W. D. Nix, "Shear bands and cracking of metallic glass plates in bending," Journal of Applied Physics, vol. 94, no. 2, pp. 904-911, 2003.

[16] M. D. Demetriou, M. E. Launey, G. Garrett et al., "A damagetolerant glass," Nature Materials, vol. 10, no. 2, pp. 123-128, 2011.

[17] H. Choi-Yim, R. D. Conner, F. Szuecs, and W. L. Johnson, "Processing, microstructure and properties of ductile metal particulate reinforced $\mathrm{Zr}_{57} \mathrm{Nb}_{5} \mathrm{Al}_{10} \mathrm{Cu}_{15.4} \mathrm{Ni}_{12.6}$ bulk metallic glass composites," Acta Materialia, vol. 50, no. 10, pp. 2737-2745, 2002.

[18] H. Choi-Yim, R. Busch, and W. L. Johnson, "The effect of silicon on the glass forming ability of the $\mathrm{Cu}_{47} \mathrm{Ti}_{34} \mathrm{Zr}_{11} \mathrm{Ni}_{8}$ bulk metallic glass forming alloy during processing of composites," Journal of Applied Physics, vol. 83, no. 12, pp. 7993-7997, 1998.

[19] F. Szuecs, C. P. Kim, and W. L. Johnson, "Mechanical properties of $\mathrm{Zr}_{56.2} \mathrm{Ti}_{13.8} \mathrm{Nb}_{5.0} \mathrm{Cu}_{6.9} \mathrm{Ni}_{5.6} \mathrm{Be}_{12.5}$ ductile phase reinforced bulk metallic glass composite," Acta Materialia, vol. 49, no. 9, pp. 1507-1513, 2001.

[20] Z. Zhu, H. Zhang, Z. Hu, W. Zhang, and A. Inoue, "Taparticulate reinforced Zr-based bulk metallic glass matrix composite with tensile plasticity," Scripta Materialia, vol. 62, no. 5, pp. 278-281, 2010.

[21] M. L. Lee, Y. Li, and C. A. Schuh, "Effect of a controlled volume fraction of dendritic phases on tensile and compressive ductility in La-based metallic glass matrix composites," Acta Materialia, vol. 52, no. 14, pp. 4121-4131, 2004.

[22] H. Tan, Y. Zhang, and Y. Li, "Synthesis of La-based in-situ bulk metallic glass matrix composite," Intermetallics, vol. 10, no. 1112, pp. 1203-1205, 2002.

[23] U. Kuhn, J. Eckert, N. Mattern, and L. Schultz, "Microstructure and mechanical properties of slowly cooled $\mathrm{Zr}-\mathrm{Nb}-\mathrm{Cu}-\mathrm{Ni}-$ Al composites with ductile bcc phase," Materials Science and Engineering A, vol. 375-377, pp. 322-326, 2004.

[24] C. Fan, R. T. Ott, and T. C. Hufnagel, "Metallic glass matrix composite with precipitated ductile reinforcement," Applied Physics Letters, vol. 81, no. 6, pp. 1020-1022, 2002.

[25] U. Kühn, J. Eckert, N. Mattern, and L. Schultz, “ZrNbCuNiAl bulk metallic glass matrix composites containing dendritic bcc phase precipitates," Applied Physics Letters, vol. 80, no. 14, pp. 2478-2480, 2002.

[26] D. C. Hofmann and W. L. Johnson, "Improving ductility in nanostructured materials and metallic glasses: "three laws'," Materials Science Forum, vol. 633-634, pp. 657-663, 2010.

[27] D. C. Hofmann, J. Y. Suh, A. Wiest et al., "Designing metallic glass matrix composites with high toughness and tensile ductility," Nature, vol. 451, no. 7182, pp. 1085-1089, 2008. 
[28] E. Soinila, T. Pihlajamäki, S. Bossuyt, and H. Hänninen, "A combined arc-melting and tilt-casting furnace for the manufacture of high-purity bulk metallic glass materials," Review of Scientific Instruments, vol. 82, no. 7, Article ID 073901, 2011.

[29] W. L. Johnson, G. Kaltenboeck, M. D. Demetriou et al., "Beating crystallization in glass-forming metals by millisecond heating and processing," Science, vol. 332, no. 6031, pp. 828-833, 2011.

[30] J. Schroers, "Processing of bulk metallic glass," Advanced Materials, vol. 22, no. 14, pp. 1566-1597, 2010.

[31] A. Wiest, G. Duan, M. D. Demetriou et al., "Zr-Ti-based Be-bearing glasses optimized for high thermal stability and thermoplastic formability," Acta Materialia, vol. 56, no. 11, pp. 2625-2630, 2008.

[32] G. Duan, A. Wiest, M. L. Lind, A. Kahl, and W. L. Johnson, "Lightweight Ti-based bulk metallic glasses excluding late transition metals," Scripta Materialia, vol. 58, no. 6, pp. 465-468, 2008.

[33] G. Duan, A. Wiest, M. L. Lind, J. Li, W. K. Rhim, and W. L. Johnson, "Bulk metallic glass with benchmark thermoplastic processability," Advanced Materials, vol. 19, no. 23, pp. 4272-4275, 2007.

[34] D. C. Hofmann, J. Y. Suh, A. Wiest, and W. Johnson, "New processing possibilities for highly toughened metallic glass matrix composites with tensile ductility," Scripta Materialia, vol. 59, no. 7, pp. 684-687, 2008.

[35] G. Kumar, A. Desai, and J. Schroers, "Bulk metallic glass: the smaller the better," Advanced Materials, vol. 23, no. 4, pp. 461-476, 2011.

[36] M. Carmo, R. C. Sekol, S. Ding, G. Kumar, J. Schroers, and A. D. Taylor, "Bulk metallic glass nanowire architecture for electrochemical applications," ACS Nano, vol. 5, no. 4, pp. 2979-2983, 2011.

[37] R. Martinez, G. Kumar, and J. Schroers, "Hot rolling of bulk metallic glass in its supercooled liquid region," Scripta Materialia, vol. 59, no. 2, pp. 187-190, 2008.

[38] G. Kumar, P. A. Staffier, J. Blawzdziewicz, U. D. Schwarz, and J. Schroers, "Atomically smooth surfaces through thermoplastic forming of metallic glass," Applied Physics Letters, vol. 97, no. 10, Article ID 101907, 2010.

[39] G. Kumar, H. X. Tang, and J. Schroers, "Nanomoulding with amorphous metals," Nature, vol. 457, no. 7231, pp. 868-872, 2009.

[40] B. Zhang, D. Q. Zhao, M. X. Pan, W. H. Wang, and A. L. Greer, "Amorphous metallic plastic," Physical Review Letters, vol. 94, no. 20, Article ID 205502, 2005.

[41] J. Schroers, Q. Pham, and A. Desai, “Thermoplastic forming of bulk netallic glass-a technology for MEMS and microstructure fabrication," Journal of Microelectromechanical Systems, vol. 16, no. 2, pp. 240-247, 2007.

[42] Y. Wu, Y. Xiao, G. Chen, C. T. Liu, and Z. Lu, "Bulk metallic glass composites with transformationMediated work-hardening and ductility," Advanced Materials, vol. 22, no. 25, pp. 2770-2773, 2010.

[43] S. Pauly, G. Liu, G. Wang et al., "Modeling deformation behavior of $\mathrm{Cu}-\mathrm{Zr}-\mathrm{Al}$ bulk metallic glass matrix composites," Applied Physics Letters, vol. 95, Article ID 101906, 2009.

[44] D. C. Hofmann, H. Kozachkov, H. E. Khalifa et al., "Semi-solid induction forging of metallic glass matrix composites," Journal of the Minerals, Metals and Materials Society, vol. 61, no. 12, pp. 11-17, 2009.
[45] D. C. Hofmann, J. Y. Suh, A. Wiest, M. L. Lind, M. D. Demetriou, and W. L. Johnson, "Development of tough, lowdensity titanium-based bulk metallic glass matrix composites with tensile ductility," Proceedings of the National Academy of Sciences of the United States of America, vol. 105, no. 51, pp. 20136-20140, 2008.

[46] J. L. Cheng, G. Chen, F. Xu, Y. L. Du, Y. S. Li, and C. T. Liu, "Correlation of the microstructure and mechanical properties of Zr-based in-situ bulk metallic glass matrix composites," Intermetallics, vol. 18, no. 12, pp. 2425-2430, 2010.

[47] J. W. Qiao, J. T. Zhang, F. Jiang et al., "Development of plastic Tibased bulk-metallic-glass-matrix composites by controlling the microstructures," Materials Science \& Engineering A, vol. 527, no. 29-30, pp. 7752-7756, 2010.

[48] J. W. Qiao, S. Wang, Y. Zhang, P. K. Liaw, and G. L. Chen, "Large plasticity and tensile necking of Zr-based bulk-metallic-glassmatrix composites synthesized by the Bridgman solidification," Applied Physics Letters, vol. 94, no. 15, Article ID 151905, 2009.

[49] J. L. Cheng, G. Chen, F. Xu, Y. L. Du, Y. S. Li, and C. T. Liu, "Correlation of the microstructure and mechanical properties of Zr-based in-situ bulk metallic glass matrix composites," Intermetallics, vol. 18, no. 12, pp. 2425-2430, 2010. 

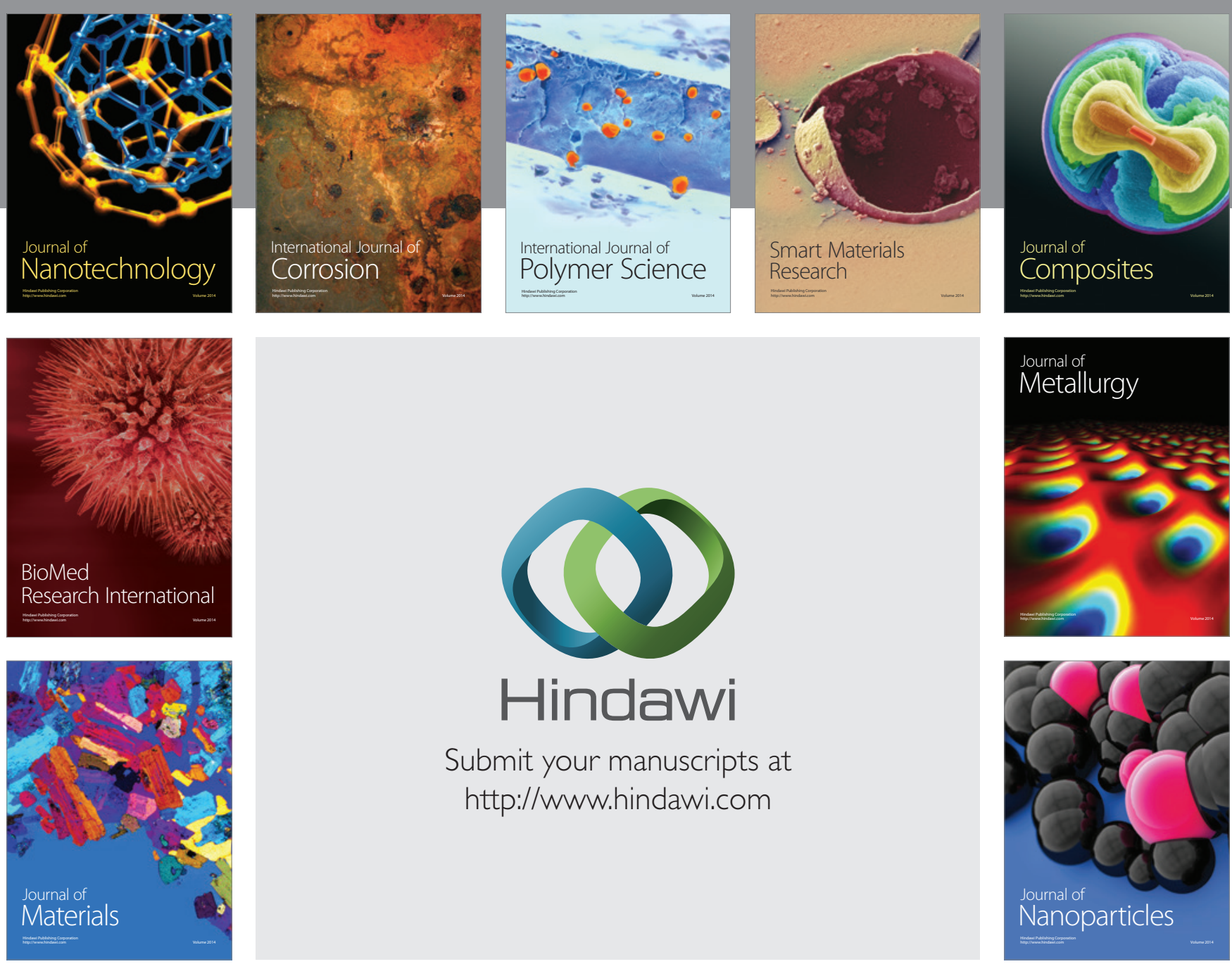

Submit your manuscripts at http://www.hindawi.com
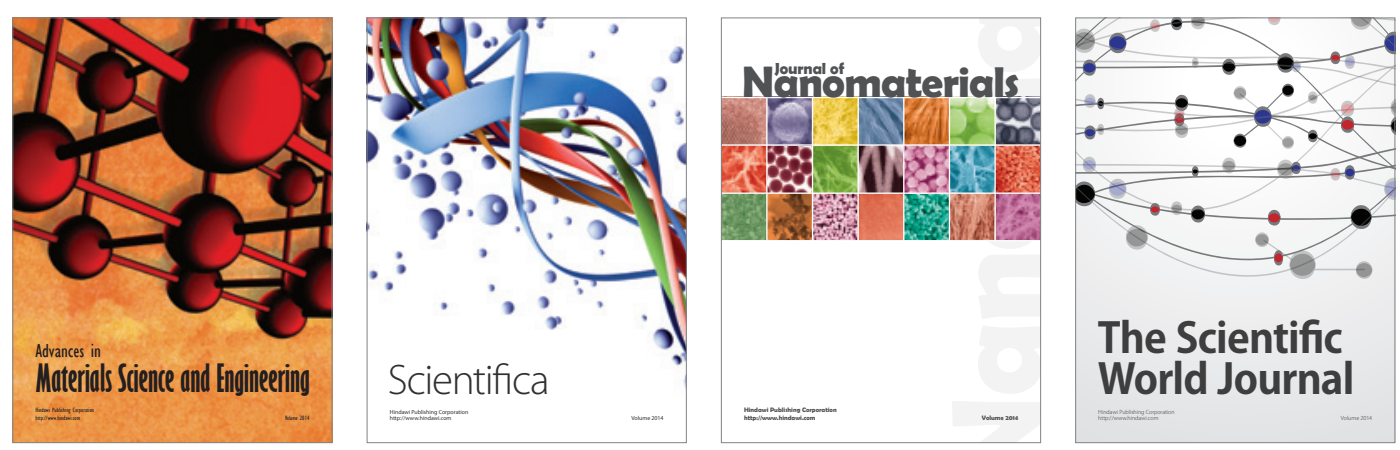

\section{The Scientific World Journal}
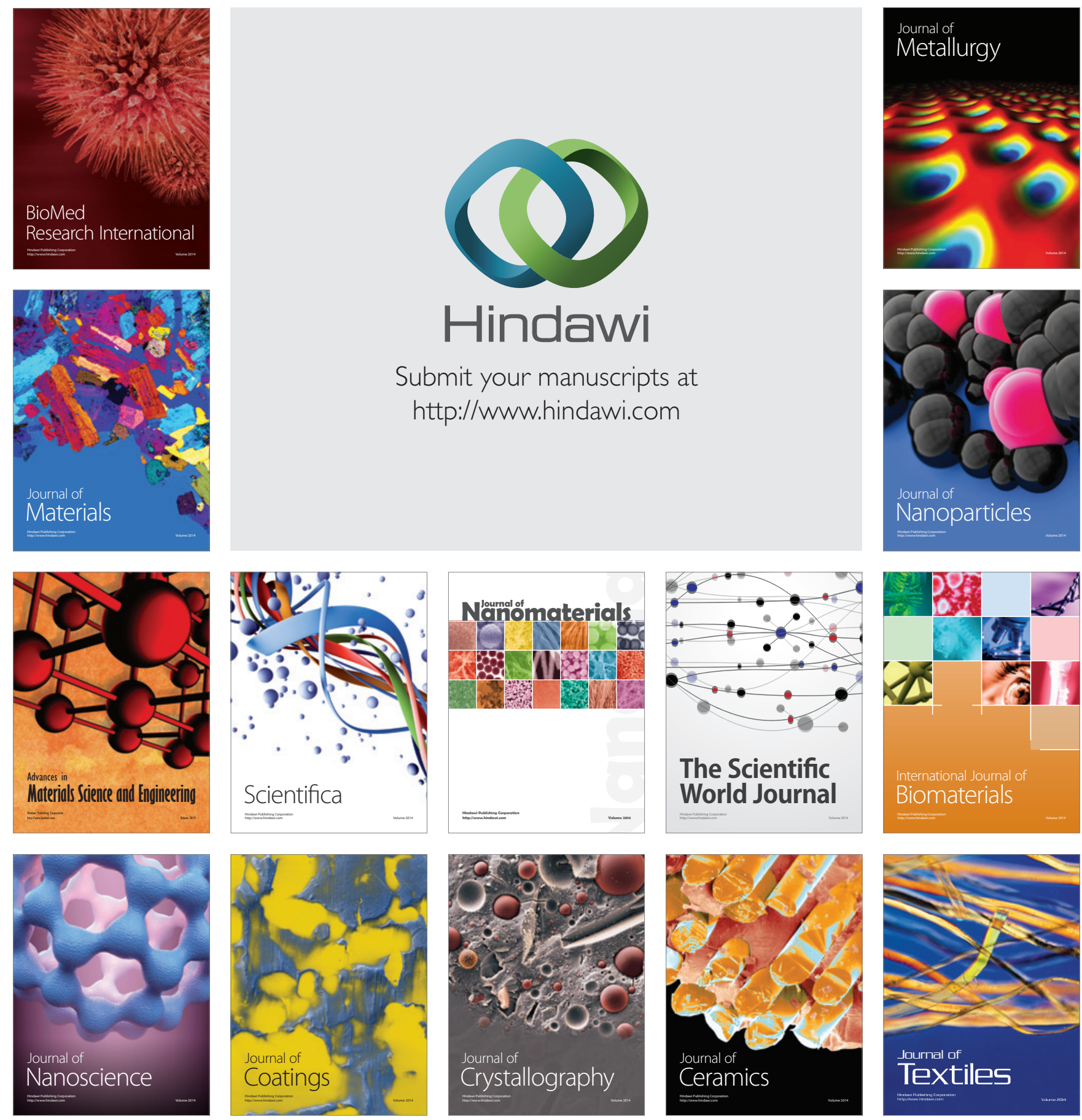